This item was submitted to Loughborough's Research Repository by the author.

Items in Figshare are protected by copyright, with all rights reserved, unless otherwise indicated.

\title{
Studying a population undergoing nutrition transition: a practical case study of dietary assessment in urban South African adolescents
}

PLEASE CITE THE PUBLISHED VERSION

PUBLISHER

(c) Taylor \& Francis

VERSION

AM (Accepted Manuscript)

LICENCE

CC BY-NC-ND 4.0

\section{REPOSITORY RECORD}

Zingoni, Chiedza, Shane A. Norris, Paula L. Griffiths, and Noel Cameron. 2019. "Studying a Population Undergoing Nutrition Transition: A Practical Case Study of Dietary Assessment in Urban South African Adolescents". figshare. https://hdl.handle.net/2134/6432. 
This item was submitted to Loughborough's Institutional Repository (https://dspace.lboro.ac.uk/) by the author and is made available under the following Creative Commons Licence conditions.

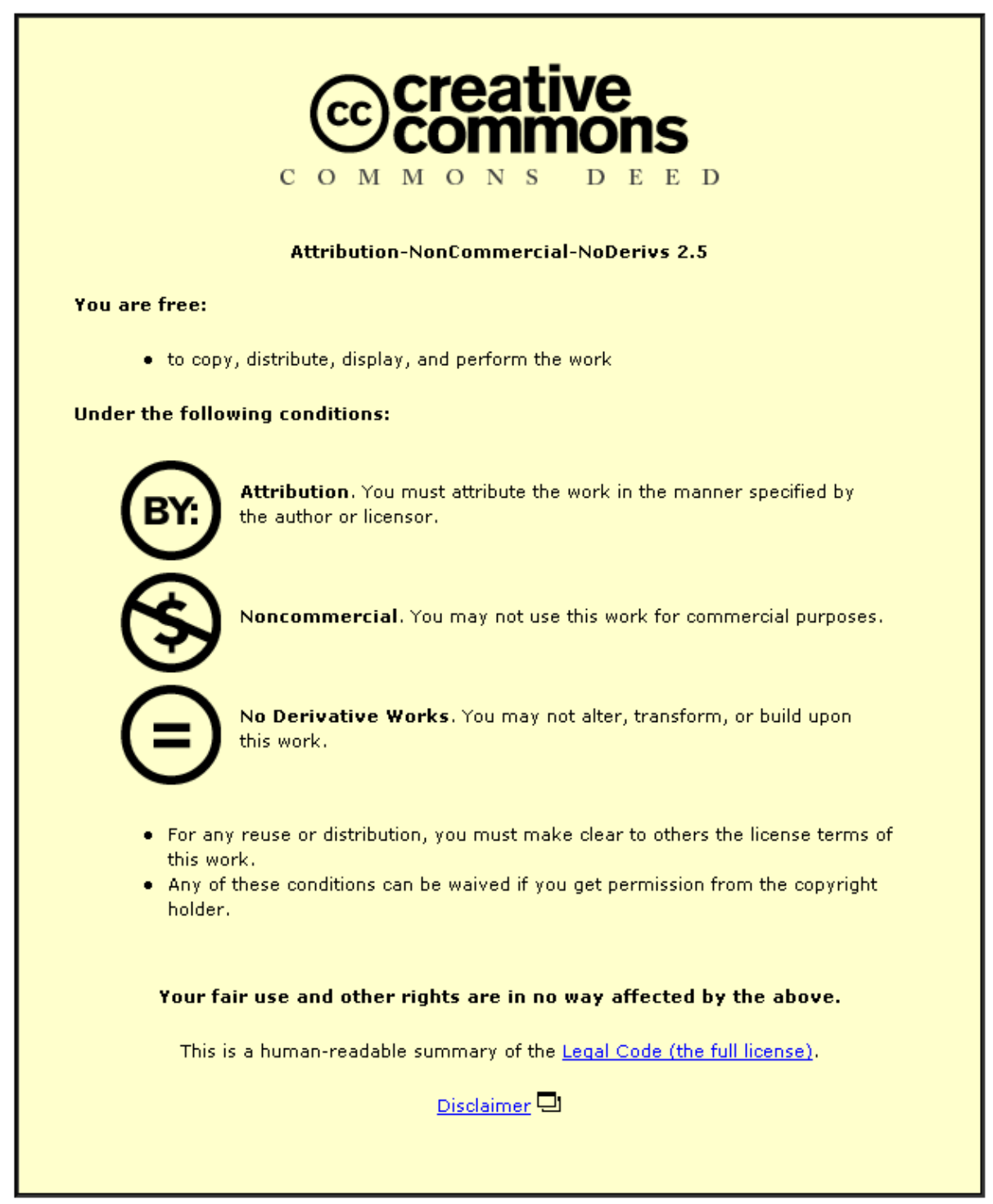

For the full text of this licence, please go to: http://creativecommons.org/licenses/by-nc-nd/2.5/ 
Studying a population undergoing nutrition transition: a practical case study of dietary assessment in urban South African adolescents.

Abstract word count: 97 (max.100)

Text word count: 5774

Number of tables: 3

Number of figures: 1

Shortened version of title: A case study of dietary assessment in South African adolescents. 
Studying a population undergoing nutrition transition: a practical case study of dietary assessment in urban South African adolescents.

\section{Chiedza Zingoni}

Department of Human Sciences, Loughborough University, LE11 3TU, UK

\section{Shane A. Norris}

MRC Mineral Metabolism Research Unit, University of the Witwatersrand, South Africa.

\section{Paula L. Griffiths}

Department of Human Sciences, Loughborough University, LE11 3TU, UK and MRC Mineral Metabolism Research Unit, University of the Witwatersrand, South Africa

\section{Noël Cameron}

Department of Human Sciences, Loughborough University, LE11 3TU, UK and MRC Mineral Metabolism Research Unit, University of the Witwatersrand, South Africa

Address correspondence to Paula Griffiths, Department of Human Sciences, Loughborough University, LE11 3TU, UK. Email: P.Griffiths@lboro.ac.uk 


\section{Abstract}

The South African Medical Research Council food frequency questionnaire (FFQ) and protocol was used to determine food intake in 83 adolescents from the Birth To Twenty study. The FFQ was piloted on a small group $(n=8)$. Specific problems which resulted in overestimation of energy intake were identified. The protocol was modified and administered to the remainder of the adolescents and their caregivers. Reasonable energy intakes were obtained, and time spent completing the FFQ was reduced. The modified protocol was more successful in determining habitual food intake although it would benefit from validation against other dietary intake techniques.

KEYWORDS: dietary assessment, adolescents, food frequency questionnaire, nutrition transition.

\section{Introduction}

The end of apartheid in South Africa initiated dramatic demographic, sociopolitical, and economic transitions. Coupled with these changes, there has been rapid urbanization of the Black South African population (Lester et al., 2000). The average annual growth rate of South Africa's urban population reached 2.9\% between 1990 and 2004 (UNICEF, 2006). In developed countries, research has shown that urbanization increases the risk of nutritionrelated non-communicable diseases (NCDs) such as obesity, diabetes and cardiovascular diseases. This increased risk has been attributed to a "nutrition transition" which is characterized by a decline in the consumption of foods which are low in fat, high in unrefined carbohydrate, and fibre to the so called 
'western' diet with increased fat, sugar, salt and refined foods (Popkin, 1994). Global evidence on the nutrition transition is mostly based on national aggregate data from food balance sheets which use food availability as a proxy for dietary intake (Popkin, 1994; Kelly et al., 1991). These studies are population based with no focus on children or adolescents as a separate group. The lack of data on children and adolescents is problematic as it is during this time in the life course that eating attitudes, behaviours and patterns are being formed (Kelder et al., 1994; Moore, 1993; Nicklas, 1995) in addition to being an important period in the aetiology of obesity and adult NCDs (McGill, 1997; Dietz, 1994; Power et al., 1997).

\section{Evidence of a nutrition transition in South Africa}

The "nutrition transition" is typically described as a shift towards an 'unhealthy' diet which is high in total fat, saturated fat, added sugar and salt from one that is rich in whole grains, fruits, vegetables and low in fat. The range of recommended population nutrient intake goals are $15-30 \%$ fat, $55-75 \%$ carbohydrate, $10-15 \%$ protein and $<10 \%$ added sugar of total energy intake (WHO/FAO, 2003). In South Africa food balance sheets between 1962 and 2001 have shown an increase in per capita food and energy availability. An increase in energy supply of $318 \mathrm{kcal}$ was observed and a transition to increased fat intakes is evident. As a proportion of total energy the macronutrient composition was $21.2 \%$ fat, $68.3 \%$ carbohydrate and $10.5 \%$ protein in 1962 , and $24.3 \%$ fat, $65.4 \%$ carbohydrate and $10.3 \%$ protein in 2001 suggesting a nutrition transition was in progress (FAO, 2004; Steyn et al., 2006a). These figures give an indication of the available food but not how 
they are distributed by age, gender or socioeconomic status (Steyn et al., 2006).

A study of five-year-old urban black South African children in 1984 and 1995 revealed a shift towards a more 'western' diet: In 1984, a diet which was 30\% fat and 61\% carbohydrate was consumed. By 1995, fat intake had increased to $41 \%$ of total energy while carbohydrate intake had decreased to $52 \%$ (Mackeown et al., 1998). The BRISK study of an urban African population in the Cape Peninsula in 1990 revealed intakes of $27 \%$ fat, $64 \%$ carbohydrate and $13 \%$ protein in the 15-18year age group using 24 hour recall (Bourne et al., 1993). In the THUSA study (Transition, Health and Urbanization in South Africa) conducted in 1996 and 1998 a quantitative FFQ was used to assess diet in a sample aged between $15-80$ years and data are presented by gender and urbanization strata. Dietary intakes were shown to be changing from a traditional diet to a high-fat low-fibre diet. The mean intake of the upper urban class stratum was 31\% fat, 57\% carbohydrate and 13\% protein (Maclntyre et al., 2002). In the THUSA BANA (BANA means children) study in $2000-2001$ dietary intake was assessed in 10-15 year-olds ( $n=1257)$ using a 24-hour recall. Fat intakes were between $26-27 \%$ of total energy intake for the different urbanization strata (Kruger et al., 2005).

Current evidence therefore suggests that the nutrition transition is underway in South Africa. Accompanying this is an increase in nutrition-related non communicable diseases (Popkin, 1994). Most of the nutrition transition literature focuses on adults and we know comparatively little about children 
and adolescents. The consequences of the nutrition transition are already evident in that obesity is an increasing health concern with an overweight and obesity prevalence of $17.6 \%$ and $5.9 \%$ in adolescent girls and $5.3 \%$ and $2 \%$ in boys respectively (Department of Health, 2002). Adolescence is an important period in the formation of eating attitudes and behaviours and dietary habits formed during this stage of life have considerable impact on long term health status (McGill, 1997; Dietz, 1994; Power et al., 1997; Kelder et al., 1994). Therefore dietary intake patterns need to be assessed in order to inform future interventions that attempt to counteract the negative consequences of nutrition transition. However, limited dietary intake research on adolescents has been conducted in South Africa.

The aim of this study was to extend our knowledge base on dietary intake in adolescents. As no food frequency questionnaire (FFQ) has been developed specifically for adolescents in South African, there is thus a need to develop or modify existing dietary methods to make them suitable for this particular age group, their abilities and motivation levels to understand appropriately the dietary intake of adolescents in South Africa (Livingstone and Robinson, 2000). Teufel (1997) describes such a modified FFQ as a 'culturally competent tool' which takes into consideration the unique behaviour of a population and accommodates this in a useful way to work in the given study context. This is because communities are different in their development and needs, and even more so for South Africa because of its unique history. In this paper we describe the selection of the dietary tool and its subsequent modification for use with this South African adolescent population. 


\section{Assessing dietary intake}

Dietary intake can be assessed by a variety of methods such as 24 hour recalls, weighed or estimated food records, food frequency questionnaires and dietary histories (Willet, 1990). It is generally accepted that there is no ideal method for dietary intake assessment as all methods have limitations associated with them. The chosen method will depend on sample size and the characteristics of study participants, respondent burden, the skills of research staff, available resources, and study objectives (Willet, 1990).

Both 24-hour recall and FFQ have been used to determine dietary intake in South African populations (Maclntyre et al., 2002; Steyn et al., 2000). However the 24-hour recall method has been used most frequently with South African adolescents (Wolmarans et al., 1988; Bourne et al., 1993; Steyn et al., 1993). Repeated 24-hour recalls are recommended to determine "usual intake" as single recalls are unrepresentative because of day-to-day variation (Willet, 1990; Block, 1982). No studies were identified in the literature on South African adolescents using food records to determine usual food intake. These are usually the ideal method but are impractical in most studies because of cost and respondent burden. Like the 24-hour recall they also require several days to be recorded to determine usual intake (Willet, 1990; Block, 1982). The FFQ has been shown to be a reproducible and relatively valid tool in comparison to weighed records in an African population (MacIntyre et al., 2000a; Maclntyre et al., 2000b). The FFQ was administered twice with an interval of $6-12$ weeks and the Spearman rank correlation between the two administrations ranged from 0.14 for calcium to 0.75 for 
alcohol (Maclntyre et al., 2000a). Dietary data from the FFQ was compared with 7-day weighed records in 74 participants aged 15-65 years. Spearman rank correlation coefficients ranged from 0.14 (fibre) to 0.59 (vitamin C) and were all statistically significant $(P<0.05)$ except iron and vitamin A (Maclntyre et al., 2000b). Previous studies reveal there is a good correlation between the 7-day weighed record and FFQ for nutrient intake. Correlation coefficients ranged from 0.17 to 0.54 (Lietz, et al., 2002), 0.13 to 0.33 (Robinson et al., 1999), 0.14 to 0.36 (Margetts et al., 1989), and 0.13 to 0.9 (Bingham et al., 1994. A range of $0.3-0.7$ is suggested as an indication of good agreement between the food frequency questionnaire and weighed records (Willet, 1990; Margetts et al., 1989).

The FFQ was chosen as the dietary intake assessment tool for the current study because it less time consuming and has less respondent burden and cost than other dietary assessment tools (Willet, 1990; Block, 1982). Previous South African nutritional studies using the FFQ have not specifically developed a questionnaire for adolescents (e.g. Steyn et al., 2000; Maclntyre et al., 2002) although the FFQ has been widely used to determine macronutrient intake in adolescent populations in other countries such as the USA (Rockett et al., 1995; Rockett et al., 1997), Norway (Frost Andersen et al., 1995), Belgium (Paulus et al., 2001), UK (Robinson et al., 1999) and Spain (Tur et al., 2004). These studies have developed and adapted the FFQs specifically for adolescents. 
In the current study, the FFQ developed by the South African Medical Research Council (MRC) to include relevant South African foods (Steyn and Senekal, 2005) was chosen to assess usual dietary intake in this urban adolescent population. The FFQ had not previously been used on adolescents and thus the first part of the study reports on the findings from case studies using the FFQ. A case study has the ability to highlight unique challenges encountered with a technique and will therefore inform broader research studies that wish to apply the methodology. The second part of this paper will report the dietary intake using the South African MRC FFQ methodology in a sub sample of 15-year-old urban black South African adolescents from the Birth To Twenty Cohort (Bt20) (Richter et al., 2007).

\section{Methodology}

Bt20 is a longitudinal birth cohort of children born in $1990 \quad(n=3273)$ to document the survival, health, growth, and psychosocial development of children in an urban setting in Soweto/Johannesburg, South Africa (Richter et al., 2007). A random sample of 84 black participants (47 girls and 37 boys) from the Bt20 study took part in this dietary intake study during the year 15 data collection. The Bt20 cohort consists of participants from four ethnic groups, Black (78\%), White (6\%), Coloured (12\%) and Indian (4\%) with the size of each ethnic group proportional to the total South African population (Richter et al., 2007). Evidence suggests that the Whites have already undergone the nutrition transition and have more 'westernized' lifestyles and diets (Wolmarans et al., 1988; Vorster et al., 1995) hence this study focuses on the black majority population who are currently undergoing transition. 
Historically under apartheid ${ }^{1}$ Blacks lived in townships like Soweto and Whites in suburban Johannesburg. Today racial integration has occurred but the majority of the black population still lives in Soweto.

Exclusion criteria included pregnancy and/or being on a special medically prescribed diet. Only one girl was excluded because she was pregnant and none were following a medically prescribed diet.

The MRC FFQ food list was based on an analysis of dietary surveys conducted in South Africa since 1983. The list includes all foods eaten by at least $3 \%$ of the population. A food photo manual (FPM) developed by the MRC, food flour models and household utensils were used to determine portion sizes. The FPM has been shown to assess portion size with reasonable accuracy in adolescents (Steyn et al., 2006b). Food pictures and flour models were tested in a sample of Black ( $n=50$ and White $(n=42)$ children aged $12-13$ years living in the same geographical area as the Birth To Twenty cohort. Each participant was presented with a plate of food of a known weight and was required to select a picture and flour model that resembled the portion size on the plate. Significant $(P<0.0001)$ positive linear correlations (0.842 -0.994) between the calculated nutrients using the actual and estimated portion sizes using both pictures and flour models were observed for the 11 food items tested (Steyn et al., 2006b).

\footnotetext{
${ }^{1}$ Apartheid is an Afrikaans word (South African language derived from Dutch) meaning apartness or separation. Apartheid was a national government policy introduced by the National Party after their 1948 parliamentary election victory that encouraged separate development of different population groups. Several laws were put in place to enforce this racial segregation (Lapping, 1989; Seidman, 1980)
} 
Dietary assessment was carried out in addition to a 3.5 hour routine annual visit in which anthropometry, dual-energy X-ray absorptiometry scans (DXA), Tanner scaling for pubertal development, socio-economic status, and physical activity were assessed. A single nutritionist (CZ) conducted all the dietary interviews to minimize interviewer variability. The weights of foods consumed daily were calculated by multiplying the portion weight by the frequency of consumption and dividing by the time period. The data were entered into the Foodfinder Dietary Analysis Programme to calculate individual nutrient intakes (Medical Research Council, 2002).

Using a case study approach, during the first stage of the pilot work the FFQ was administered to 8 participants using the standard protocol (Steyn and Senekal, 2005). The protocol was then modified according to practical experiences and logistical problems identified and applied to a further 75 participants.

\section{Ethical considerations}

Ethical approval for this study was obtained from the University of the Witwatersrand, South Africa and Loughborough University, UK ethical advisory committees. Informed consent and assent was sought from the caregiver and the adolescent participant. The caregiver in the Bt20 study refers to the person who is primarily responsible for the welfare of the adolescent. In this study the majority of the caregivers are the parents, with 
the remainder being other family members including aunts, uncles or grandparents.

\section{Results and Discussion}

Time and Motivation: Using the standard MRC protocol, the entire interview took on average 60minutes depending on the responsiveness of the adolescent. The length of the interview was too long considering the adolescents had already undergone 3.5 hours of routine annual assessments. The tool therefore needed modification to reduce the amount of time spent with the adolescent participant.

By the end of the case study interviews the adolescents appeared disengaged and a set response format developed, which could not be overcome with probing and encouragement from the interviewer. The interviewer concluded that the participants were bored through observation of certain behavioral attributes of participants which included increased restlessness, nonresponsiveness, and development of a set response format. Participants also made inquiries as to when the interview process would end. As these participants were part of an ongoing longitudinal study it was crucial to maintain their motivation and not deter them from future visits.

In order to reduce respondent burden and maintain motivation it was decided to modify step 2 and 3 in the methodology shown in Fig 1 (Steyn and Senekal, 2005) to the following: "Please look through these photographs and make three piles. One pile is for items, which you never ate/drank, one for those you 
ate drank occasionally that is only once or twice a month, and the other is for the foods you eat everyday or week." Put away the pile of cards that were not eaten or drunk. Indicate the foods that were eaten occasionally and those never eaten by ticking the respective columns. Instead of quantifying all of the foods it was decided to quantify only the foods eaten every day or every week. This was done to limit the interview time as the foods would make a small contribution to overall macronutrient intake if they were not eaten on a regular basis.

The modification resulted in the dietary interview taking a shorter time to complete. On average this was 45 minutes with only about 20 minutes being spent with the adolescent (also because of caregiver involvement described in subsequent sections). The adolescents did not appear to get bored as time spent with them was minimal i.e. 20 minutes in comparison to 60 minutes with the first group. The adolescents were more responsive, and did not enquire as to when the interview would end.

Time is a major factor in any study especially when working with children or adolescents. In order to avoid loss of participants in any longitudinal nutritional study it is important to take the shortest possible time and prevent boredom without jeopardizing data quality. The modified methodology reduced the time spent with the adolescent considerably. It has been shown that adolescents are capable of providing food intake data using all usual methods, although they become bored quickly by dietary intake assessments. This can result in a lack of compliance and poor data quality (Livingstone and Robson, 2000). 
Dietary assessment methods that are less time consuming are therefore more likely to improve responsiveness and hence data quality when collecting information from adolescents.

Ability: It was apparent that some participants found it difficult to answer the FFQ and took more time before giving a response. The organization of foods into food groups made it difficult for the adolescents to answer the FFQ. For example, asking about bread and then spreads at different places in the questionnaire. Participants tended to respond by saying 'I eat bread with butter and cheese'. This meant that they were frustrated when later asked about spreads in another section of the FFQ. Michela and Contento (1984) reported that children perceive and organize foods in memory differently in comparison to investigators. It is therefore important to observe participants of each age group and cultural background to enable use of appropriate prompts to aid recall. It has been suggested that this can be achieved by modifying the questioning to reflect the eating patterns of the group under investigation (Livingstone and Robson, 2000). Thus, it was decided to reorganize the foods in the MRC FFQ to fit with the way in which adolescents had clustered foods during the pilot case study.

Modification: The structure of the questionnaire was changed so that foods eaten together were grouped together, for example, bread and spreads, porridge and milk, sugar, butter/margarine. This was adapted from the FFQ used by Maclntyre (1998) and gives a flow to the questionnaire preventing monotony. There were other changes that would have been logical to make 
e.g. grouping main carbohydrate dishes such as stiff maize porridge (pap), rice, or pasta with meat. However it was not possible to restructure the whole questionnaire as the way it was arranged originally made it easier to use the food photo manual (FPM). The FPM was colour coded with each colour representing different food groups and the foods within each section were also arranged alphabetically. To change these orderings would have made the original toolkit unusable. Future studies should consider testing the viability of regrouping more foods with a redesigned manual to enable the tool to be user friendly within the field.

Arranging the foods according to how they were eaten made it easier for the adolescent to recall what they had eaten. The ability to answer the FFQ improved with the changes in the structure of the questionnaire. Grouping foods eaten together appeared to simplify recall and quantification. Participants seemed to think in terms of meals and not food groups (Maclntyre, 1998).The MRC tool was structured in terms of food groups making it hard for participants to comprehend. According to Teufel (1997) the groupings which facilitate dietary reporting in a particular group may seem counterintuitive to the researchers especially if they are from a different cultural background. This highlights the importance of piloting the dietary intake tool to ensure that the arrangement fits within the respondent's conceptual framework.

Quantification and brand names: The quantification of added ingredients during cooking and food preparation was also a problem for adolescents since 
they said they were not actively involved in food preparation. Some indicated that they were also not aware of the cooking methods. The adolescents also had difficulties in naming the brand/types of food eaten at home e.g. differentiating between skim and full cream milk, or margarine and butter. Some adolescents mentioned that they just use the food available and do not look at the description, to quote one participant "I just use what is in the fridge". Questions on food preparation and ingredients in composite meals were also said to complicate the completion of the FFQ in a study of UK adolescents (Lietz et al., 2002), meaning that this is not a unique finding for adolescents within the South African context.

Therefore, there was a need to find something to aid these participants in the current study to recall brand names and quantities of what they ate. Studies of younger participants are usually done with the parent/guardian of the child (Livingstone and Robson, 2000). Some studies have shown that comparison of results of direct observation of children with 24 hour dietary recalls by the parents provided reliable data of the children's intake in the home setting (Baranowski et al., 1991, Basch et al., 1990 and Eck et al., 1989). It was therefore possible that the difficulties that participants had recalling quantities and brands could be solved by including the caregiver in the interview process. Whilst adolescents in other countries managed to complete dietary interviews on their own (Park et al., 2004, Tur et al., 2004; French et al., 2001; Lietz et al., 2002; Samuelson et al., 1996), capabilities of South African black adolescents could differ from adolescents in developed nations. 
Modification: In order to counteract the problem of quantification of added ingredients during food preparation, and brand/types of foods consumed at home, it was decided to involve the caregiver in the interview. A trial interview with an adolescent together with their caregiver was conducted. The adolescent sorted the cards with the caregiver's help and they helped each other quantify the foods. The interview took 35 minutes to complete and the adolescent participant did not appear as bored as in previous interviews. The concern with this approach however was that the adolescent might not mention some of the foods consumed if they were disapproved of by the caregiver. One female adolescent in the previous interviews, for instance, stated that her mother would be very upset if she knew she was eating a lot of 'junk' food. The unspoken interaction between the adolescent and caregiver when going through the snacks and alcohol cards in the first caregiver and adolescent interview suggested that there was a possibility of the adolescent withholding some of the information about foods which were disapproved of by the caregiver and eaten in their absence.

To overcome this problem, it was decided to ask the adolescent to complete the sorting in the absence of the caregiver. This way all foods eaten would be selected without fear of disapproval. The adolescent was then asked to sort the usually eaten pile into foods eaten at home and outside the home (e.g. school, friend's houses) where the caregiver was absent. The adolescent was asked to quantify the foods consumed away from home in the absence of the caregiver, and then the caregiver was asked about the foods consumed at 
home separately as caregivers have been shown not to be reliable reporters of foods eaten out of home (Baranowski et al., 1991).

When the caregiver was not involved in the dietary intake interview in the original methodology, it meant that there was no one available to clarify any information that the adolescent could not provide such as the method of cooking i.e. fried, roasted, boiled etc., ingredients added during cooking and their quantities as well as brand names of foods eaten at home. Involving the caregiver in the dietary interview whilst shortening the time spent with the adolescent also meant that more information could be collected on food brands as well as ingredients added during cooking. The caregivers were knowledgeable about the brands of foods eaten at home as they were the ones involved in shopping for the food consumed at home. They were also actively involved in food preparation and knew what ingredients had been added to the food. It was however difficult to get a usual preparation method as the caregiver would say "it differs from day to day, sometimes, I fry, boil, grill, it just depends". This was overcome by asking for the most frequently used method.

If the caregiver was hesitant or could not quantify any additions to food (such as sugar in tea) these were flagged and the adolescent asked at a later stage. In a few cases where the caregiver said the food was never consumed at home it was noted and not quantified. This could be because there is always a possibility of recognition errors in dietary intake studies whereby foods are recalled as eaten when they are not (Livingstone and Robinson, 2000). Smith 
(1991) calls these "phantom foods" or "intrusions". These are foods selected by the respondent as being consumed because they are believed to be "healthy" such as vegetables or because they feel they have not selected many of the foods on the given list (Smith, 1991). It is critical that the interviewers are well trained that they remain neutral regardless of the responses participants give.

Energy intakes: The daily energy intakes of the participants using the standard protocol were calculated and the results are shown in Table 1. The range was $1681-6590 \mathrm{kcal}$ and mean intake for girls and boys were $3599 \mathrm{kcal}$ and $5978 \mathrm{kcal}$ respectively. These averaged $181 \%$ of the Recommended Dietary Allowance (RDA) (Food and Nutrition Board, 1989). These intakes are extremely high considering that only two of these participants were overweight and none were obese according to age adjusted Body Mass Index (BMI) cutoffs (Cole et al., 2000). Even if very high levels of physical activity are assumed the intakes are still remarkable.

Disengagement and difficulty in quantification, cooking methods and naming brands could contribute to the unreasonable energy intakes. In addition to these problems, an observation was also made that participants tended to say that they ate a food everyday even if it was for 5 or 6 days a week meaning that it was essential to probe such responses with 'so is it Sunday to Saturday?' This was a particular problem because it could result in overestimating intakes if the food was only eaten on 5 days but the participant reported that it was eaten daily. As an example, the participant would say they 
ate either pap or rice as the main meal of the day accompanied by some sort of relish. When the participant said they ate pap everyday the interviewer probed them to say how many days they ate pap and rice since their initial response implied that it was not consumed everyday. Since pap is a staple food for Blacks in South Africa, it is essential that frequency of consumption is accurate as errors will distort the nutrient intake significantly (Venter et al., 2000).

The interviewer therefore changed the way frequency questions were asked to avoid the adolescent getting into a pattern of answering. For example, asking which days of the week they ate the food instead of just asking how many times they consumed the food. This also was intended to reduce the likelihood of the respondent answering everyday if they actually only consumed the food on five days of the week.

The energy intakes of the group using the modified procedure are shown in Table 2. Mean energy intakes were more reasonable in comparison to the other group. Intakes averaged $111 \%$ of the RDA compared to $181 \%$ in the original methodology. The prevalence of overweight/obesity in this sample was $21.4 \%$ and $6 \%$ in girls and boys respectively. The energy RDA is the mean requirement for a group and intakes which exceed these requirements will result in positive energy balance and therefore overweight/obesity in the long run $(\mathrm{WHO}, 1985)$. Intakes before modification of the FFQ therefore suggest overestimation when they are compared with the BMI of the 
participants whereas those after modification are more plausible in relation to their BMI values.

To contextualise the dietary intake findings of this study, the mean energy intakes obtained using the original MRC and the modified procedures are compared with other studies of adolescents of a similar age in South Africa in Table 3. The differing dietary methodologies, communities, specific age groups and environments make true comparisons difficult with other studies conducted in South Africa. This reflects the paucity of information available for the age group of interest. All of the studies used either the FFQ or 24-hour recall for assessing dietary intake. The errors associated with both the FFQ and 24-hour recall are correlated i.e. perceptions of serving sizes and memory (Willet, 1990). Significant correlations ranging from 0.32 to 0.56 for macronutrients have been observed between the FFQ and the 24-hour dietary recall (Sichieri et al., 1998 and Hernandez-Avila et al., 1998). The studies are therefore comparable to some extent. It cannot be ascertained however how much of the differences in intake can be explained by the dietary intake methods used across studies. Nevertheless the combined evidence from these studies suggests that this study before modification overestimated intakes. The intakes are much higher than those obtained in a white sample which has already transitioned to a 'western' diet (Wolmarans et al., 1988).

After the FFQ was modified the energy intakes were similar to that of the white sample for males (Wolmarans et al., 1988), possibly suggesting that this group of urban South African black males has transitioned to a 'western diet'. 
However the black girls are consuming much more energy than the white girls (Wolmarans et al., 1988). It could be that white girls are more conscious about their body image and hence their diet in comparison to black girls. A large weight is perceived to be associated with high social status and being healthy in certain non-white groups (Williamson, 1998; Wildes et al., 2001). In South Africa qualitative research revealed that being overweight was said to reflect beauty, affluence, and health (Clark et al., 1999; Mvo et al., 1999; Puoane et al., 2002 and Caradas et al., 2001). One study has shown that South African adolescent Blacks desired significantly larger body sizes in comparison to their White peers (Caradas et al., 2001). Body size perception was however not investigated in the adolescents in the current study or by Wolmarans et al., (1988) therefore it cannot be concluded that this is responsible for the observed results. However, the energy intakes in the Wolmaran's study were much lower in females compared to males, suggesting the possibility that the females in the Wolmaran's study, who had an overweight prevalence of 28.6\%, under-reported their actual intakes.

The current study had lower intakes for the modified protocol in comparison to intakes obtained in a Black (urban and rural) population using a FFQ in the THUSA study (Maclntyre et al., 2002). Both studies used quantitative FFQs and similar methods of quantification using food portion photographs and common household utensils. The administration of the FFQ differed in that the current study involved the caregiver whilst the THUSA study did not which could explain the lower intakes in the current study as the combination of caregiver and adolescent appeared to enhance the quantification. It was 
observed that without caregiver involvement intakes were much higher before modification of the FFQ. The difference in ages of participants could also explain the difference in energy intakes as the intake is given for 14 to18year-olds in the THUSA study in comparison to 15-year-olds in the present study. Data in the THUSA study was collected in 1996 and 1998 and the Bt20 data was collected in 2005. Given that a nutrition transition is taking place in South Africa, it would have been expected that higher energy intakes would be observed in the Bt20 sample due to the nutrition transition but this is not the case. The data was not broken down by sex in the THUSA study, which makes comparisons more difficult.

Lower intakes were found in the Bourne et al. (1993) study compared to the current study. This could well be due to timing differences between the two studies, where food availability has increased over this time period. It is however difficult to make comparisons among the various studies as the intakes could be due to real differences in energy intake or could be a result of differing methodologies. What is clear from observing Table 3 is that the energy intakes observed after modification in this study fit within the range of values observed by other studies in this setting, whereas the energy values observed before modification were much higher.

\section{Limitations of using the modified approach.}

Parents of adolescents have increasingly less control over what their children eat compared to younger children. The ability of the parents to answer the FFQ would differ according to household organization and the degree of 
independence of the adolescent. Some caregivers expressed concern that they now hardly notice what their adolescent consumes especially with foods such as fruits. When fruits are available in the house the caregiver reported that it is not always possible to track how much the adolescent eats. Additional clarification from the adolescent for these types of food could therefore further improve the accuracy of this procedure.

Ingredients added during cooking such as sugar and cooking oil were difficult to quantify even for the caregiver. The caregiver was asked the number of household members for whom they were preparing food and the amount eaten by the adolescent was obtained by dividing the quantity by the number of household members. This however assumes that all of them are getting equal portions of the dish, which is not necessarily true and can result in over or underestimation of intakes.

The adolescents mentioned some foods as being eaten at home which, in a few cases, the caregiver reported as never being eaten. In this instance the foods were not quantified. This however raises a concern that the adolescents could have also mentioned some foods as eaten in the absence of the caregiver (e.g. at school) even though they were not. However, there was no way of verifying this. In this study, it was not possible to validate the modified procedure with other dietary methodologies, although this would be recommended before further use of the modified procedure. 


\section{Conclusion}

It is important to understand what urban South African adolescents are consuming in this transitioning environment because this is a critical stage in the aetiology of some adult NCDs. To do this dietary methods which assess habitual dietary intake are required. FFQs are useful for assessment of usual intake but there were clear problems with using the MRC FFQ protocol with the 15-year-olds from the Bt20 cohort. The modified protocol appeared to be more reliable with this group, although there is still a need for further validation of this tool against other dietary intake methods in subsequent studies.

Dietary intake cannot be estimated without error and the magnitude of this error will be determined by the collection methodology and subjects under investigation (Cassidy, 1994). However, this can be minimised by making the tool specific for the study population and context as shown by the improvement in the energy intakes after the modifications of the MRC tool in this paper. Researchers exploring dietary intake therefore need to assess and adapt standard methodologies to their specific research sample and environment.

\section{Acknowledgements}

BT20 is funded by the Wellcome Trust (UK), the Human Science Research Council of South Africa, the Medical Research Council (MRC) of South Africa, and University of the Witwatersrand, Johannesburg, and the Anglo-American Chairman's Fund. For information on Bt20, visit www.wits.ac.za/birthto20 
The dietary intake study was financially supported by Loughborough University, Parkes Foundation and John Guest Travelling Scholarship. Paula

Griffiths' contribution to the work is funded by the MRC, UK (grant id 70363). Shane Norris is supported by a Wellcome Trust Research Fellowship. The authors would like to extend their gratitude to the BT20 and Loughborough University research teams for their co-operation. Thanks to the adolescents and their caregivers for their participation.

\section{REFERENCES}

Baranowski, T., Sprague, D., Baranowski, J.H. and J.A. Harrison (1991). Accuracy of maternal dietary recall for preschool children. Journal of the American Dietetic Association, 91, 669-674.

Basch, C.E., Shea, S., Arliss, R., Contento, I.R., Rips, J., Gutin, B., Irigoyen, M., and P. Zybert (1990). Validation of mothers; reports of dietary intake by four to seven-year old children. American Journal of Public Health, 80, 1314-1317.

Bingham, S.A., Gill, C, Welch, A., Day, K., Cassidy, A., Khaw, K.T., Sneyd, M.J., Key, T.J.A., Roe, L. and N.E. Day (1994). Comparison of dietary assessment methods in nutritional epidemiology: weighed records $v$ 24-h recalls, food-frequency questionnaires and estimated-diet records. British Journal of Nutrition, 72, 619-643.

Block, G. A review of validations of dietary assessment methods. American Journal of Epidemiology 1982, 115,492-505

Bourne, L.T.; Langenhoven, M.L.; Steyn, K.; Jooste, P.L.; Laubscher, J.A. and E, Van der Vyfer (1993). Nutrient intake in the urban African population 
of the Cape Peninsula, South Africa. The BRISK Study. Central African Journal of Medicine, 39(12), 238-247.

Caradas, A.A., Lambert, E.V. and K.E. Charlton (2001). An ethnic comparison of eating attitudes and associated body image concerns in adolescent South African schoolgirls. Journal of Human Nutrition and Dietetics, 14, 111-120.

Cassidy, C.M. (1994). Walk a mile in my shoes: culturally sensitive food-habit research. American Journal of Clinical Nutrition, 59 (1 Suppl), 190S$197 S$.

Clark, R.A., Niccolai, L., Kissinger, P.J., Peterson, Y., and V. Bouvier (1999). Ethnic differences in body image attitudes and perceptions among women infected with human immunodeficiency virus. Journal of the American Dietetic Association, 99, 735-737.

Cole, T.J., Bellizzi, M.C., Flegal, K.M. and W.H. Dietz (2000). Establishing a standard definition for child overweight and obesity worldwide: international survey. British Medical Journal, 320, 1240-1243.

Department of Health, South African Medical Research Council and Measure DHS+ (2002). South Africa Demographic and Health Survey 1998. Full report (online). Available http://www.doh.gov.za/facts/1998/sadhs98/chapter9.pdf - accessed 13 November 2006).

Dietz, W.H. (1994). Critical periods in childhood for the development of obesity. American Journal of Clinical Nutrition, 59, 955-959. 
Eck, L.H., Klesges, R.C. and C.L. Hanson (1989). Recall of a child's intake from one meal: are parents accurate? Journal of the American Dietetic Association, 62, $409-415$.

Faber, M., Smuts, C.M., and A.J.S. Benade (1999). Dietary intake of primary school children in relation to food production in a rural area in KwaZuluNatal, South Africa. International Journal of Food Science and Nutrition, 50, 57-64.

FAO (2004). Food balance sheets. Available online: http://www.fao.org/faostat (accessed 20 July 2005).

Food and Nutrition Board (1989). National Research Council. National Academy of Sciences. Recommended dietary allowances. $10^{\text {th }}$ ed. Washington, DC: National Academy Press.

French, S.A., Story, M., Neumark-Sztainer, D., Fulkerson, J.A. and P. Hannan (2001). Fast food restaurant use among adolescents: associations with nutrient intake, food choices and behavioural and psychosocial variables. International Journal of Obesity, 25, 1823-1833.

Frost Andersen, L., Nes, M., Lillegaard, I.T., Sandstad, B., Bjorneboe, G. and C.A. Drevon (1995). Evaluation of a quantitative food frequency questionnaire used in a group of Norwegian adolescents. European Journal of Clinical Nutrition, 49, 543-554.

Hernandez-Avila, M., Romieu, I., Parra, S., Hernandez-Avila, J., Madrigal, H., and W. Willet (1998). Validity and reproducibility of a food frequency questionnaire to assess dietary intake of women living in Mexico. Salud Pub Mex, 39, 133-140. 
Kelder, S.D., Perry, C.L., Klepp, K.I. and L.L. Lytle (1994). Longitudinal tracking of adolescent smoking, physical activity, and food choice behaviours. American Journal of Public Health, 84, 1121-1126.

Kelly, A., Becker, W., and E. Helsing (1991). Food balance sheets. In food and health data: their use in nutrition policy making. WHO regional publications, European series, no. 34, pages 39-48. (W. Becker and E. Helsing, editors). Copenhagen: WHO Regional Office for Europe.

Kruger, R., Kruger, H.S., and U.E. MacIntyre (2005). The determinants of overweight and obesity among 10-15-year-old schoolchildren in the North West Province, South Africa- the THUSA BANA (Transition and Health during Urbanisation of South Africans; BANA, children) study. Public Health Nutrition, 9 (3), 351-358.

Kruger, H.S., de Ridder, J.H., and A.E. Piennar (2002). Overweight among children 10-15 years old in the North West Province: prevalence and associated factors. Journal of Endocrinology, Metabolism and Diabetes of South Africa, 7 (1): 37.

Lester, A., Nel, E. and T. Binns (2000). South Africa: Past, present and future. Gold at the end of the rainbow? England: Pearson Education Limited.

Lietz, G., Barton, K.L., Longbottom, P.J., and A.S. Anderson (2002). Can the EPIC food-frequency questionnaire be used in adolescent populations? Public Health Nutrition, 5 (6), 783-789.

Lapping, B. (1989). Apartheid: a history. Revised edition. George Brazillier Inc. New York.

Livingstone, M.B.E., and P.J. Robson (2000). Measurement of dietary intake in children. Proceedings of the Nutrition Society, 59 (2), 279-293. 
Macintyre, U.E., Kruger, H.S., Venter, C.S. and H.H. Vorster (2002). Dietary intakes of an African population in different stages of transition in the North West Province, South Africa: the THUSA study. Nutrition Research, 22, 239-256.

Macintyre, U.E., Venter, C.S., and H.H. Vorster (2000a). A culture-sensitive quantitative food frequency questionnaire used in an African population: 1. Development and reproducibility. Public Health Nutrition, $4(1), 53-62$.

Macintyre, U.E., Venter, C.S., and H.H. Vorster (2000b). A culture-sensitive quantitative food frequency questionnaire used in an African population: 2. Relative validation by 7-day weighed records and biomarkers. Public Health Nutrition, 4(1), 63-71.

Macintyre, U.E (1998). Dietary intakes of Africans in transition in the North West Province (thesis). Potchefstroom University for Christian Higher Education, Potchefstroom, South Africa.

MacKeown, J.M., Cleaton-Jones, P.E., Edwards, A.W., and H. TurgeonO'Brien (1998). Energy, macro- and micronutrient intake of 5-year old urban black South African children in 1984 and 1995. Paediatric and Perinatal Epidemiology, 12, 297-312.

Margetts, B.M., Cade, J.E. and C. Osmond (1989). Comparison of a food frequency questionnaire with a diet record. International Journal of Epidemiology, 18, 868-873.

McGill, H.C. (1997). Childhood nutrition and adult cardiovascular disease. Nutrition reviews, 55, S2-S11. 
Medical Research Council (2002). FoodFinder ${ }^{\mathrm{TM}} 3$ software application, Version 1. Developers: Nutritional Intervention Research Unit and Research Information Systems Division of the Medical Research Council, and Wam Technology CC, Parow Valley, South Africa: Medical Research Council.

Michela, J.L., and I.R. Contento (1984). Spontaneous classification of foods by elementary school-aged children. Health Education Quarterly, 11, $57-76$

Moore, D.C. (1993). Body image and eating behaviour in adolescents. Journal of American College of Nutrition, 12, 505-510.

Mvo, Z., Dick, J., and K. Steyn (1999). Perceptions of overweight African women about acceptable body size of women and children. Curationis, $22,27-31$

Nicklas, T.A. (1995). Dietary studies of children: The Bogalusa Heart Study Experience. Journal of the American Dietetic Association, 95, 11271133.

Park, H.S., Yim, K.S. and S. Cho (2004). Gender differences in familial aggregation of obesity-related phenotypes and dietary intake patterns in Korean families. Annals of Epidemiology, 14, 486-491.

Paulus, D., Saint-Remy, A. and M. Jeanjean (2001). Dietary habits during adolescence- results of the Belgian Adolux Study. European Journal of Clinical Nutrition, 55, 130-136.

Popkin, B.M (1994). The Nutrition Transition in low income countries: an emerging crisis. Nutrition Reviews, 52, 285-298. 
Power, C., Lake, J.K. and T.J. Cole (1997). Measurement and long term health risks of child and adolescent fatness. International Journal of Obesity and Related Metabolic Disorders, 21, 507-526.

Puoane, T., Steyn, K., Bradshaw, D., Laubscher, R., Fourie, J., Lambert, V. and N. Mbananga (2002). Obesity in South Africa: The South African Demographic and Health Survey. Obesity Research, 10 (10), 10381048.

Richter, L., Norris, S., Pettifor, J., Yach, D. and N. Cameron (2007). Cohort Profile: Mandela's Children: The 1990 Birth To Twenty Study in South Africa. International Journal of Epidemiology, 36, 504-511.

Robinson, S., Skelton, R., Barker, M., and C. Wilman (1999). Assessing the diet of adolescent girls in the UK. Public Health Nutrition, 2 (4), 571577.

Rockett, H., Breitenbach, M., Frazier, A., Witschi, J., Wolf, A., Field, A., Colditz, G.A. and G. Colditz (1997). Validation of a youth/adolescent food frequency questionnaire. Preventive Medicine, 26, pp. 808-816.

Rockett, H.R., Wolf, A.M., and G.A. Colditz (1995). Development and reproducibility of a food frequency questionnaire to assess diets of older children and adolescents. Journal of the American Dietetic Association, 95, 336-340.

Samuelson, G., Bratteby, L., Enghardt, H., and M. Hedgren (1996). Food habits and energy and nutrient intake in Swedish adolescents approaching the year 2000. Acta Paediatrica Supplement, 415, 1-20.

Seidman, J. (1980). Face-lift Apartheid: South Africa after Soweto. International Defence and Aid Fund for Southern Africa. London. 
Sichierri, R., and J.E. Everhart (1998). Validity of a Brazilian FFQ against dietary recalls and estimated energy intake. Nutrition Research, 18, 1649-1659.

Slater, B., Phillippi, S.T., Fisberg, R.M., and M.R.D.O. Latorre (2003). Validation of a semi-quantitative adolescent food frequency questionnaire applied at a public school in Sao Paulo, Brazil. European Journal of Clinical Nutrition, 57, 629-635.

Smith, A.F. (1991). Cognitive processes in long term dietary recall. National Centre for Health Statistics. US Government Printing Office, Washington, D.C. (Series 6.4 DHHS publication (PHS) 91 1079)

Steyn, N.P., Bradshaw, D., Norman, R., Joubert, J., Schneider, M., and K. Steyn (2006a). Dietary changes and the Health Transition in South Africa: Implications for Health Policy. Cape Town: South African Medical Research Council.

Steyn, N.P., Senekal, M., Norris, S.A., Whati, L., MacKeown, J.M. and J.H. Nel (2006b). How well do adolescents determine portion sizes of foods and beverages? Asia Pacific Journal of Clinical Nutrition, 15 (1), 35-42.

Steyn, N.P. and M. Senekal (2005). A guide for the use of the dietary assessment and education kit (DAEK), South Africa: Medical Research Council.

Steyn, N.P.; Senekal, M; Brtis, S. and J. Nel (2000). Urban and rural differences in dietary intake, weight status and nutrition knowledge of black female students. Asia Pacific Journal of Clinical Nutrition, 9(1), 53-59. 
Steyn, N.P., Badenhorst, C.J., and J.H. Nel (1993). The meal pattern and snacking habits of schoolchildren in two rural areas of Lebowa. South African Journal of Food Science and Nutrition, 5 (4), 112-119.

Teufel, N.I. (1997). Development of culturally competent food frequency questionnaires. American Journal of Clinical Nutrition, 65 (suppl), 1173S-1178S.

Tur, J.A., Puig, M.S., Benito, E., and A. Pons (2004). Associations between sociodemodraphic and lifestyle and dietary quality among adolescents in Palma de Mallorca. Nutrition, 20, 502-508.

UNICEF (2006) (www.unicef.org/infobycountry/southafrica statistics.html accessed 2 May 2006).

Venter, C.S., MacIntyre, U.E., and H.H. Vorster (2000). The development and testing of a food portion photograph book for use in an African population, Journal of Human Nutrition and Dietetics, 13, 205-218.

Vorster, H.H., Oosthuizen, W., Steyn, H.S., Van der Merwe, and J.P. Kotze (1995). Nutrient intakes of white South Africans - a cause for concern: The VIGHOR Study. South African Journal of Food Science and Nutrition, 7 (3), $119-126$.

WHO/FAO (2003). Diet, Nutrition and the Prevention of Chronic Diseases. Report of a Joint WHO/FAO Expert consultation. Technical Report Series 916. Geneva: WHO.

WHO (1985). Energy and protein requirements: Report of a joint FAO/WHO/UNU expert consultation. WHO technical report series no. 724, Geneva. 
Wildes, J.E., Emery, R.E. and A.D. Simons (2001). The roles of ethnicity and culture in the development of eating disturbance and body dissatisfaction: a meta analytic review. Clinical Psychology Reviews, 21, 521-551.

Willet, W (1990). Nutritional epidemiology: monographs in epidemiology and biostatics, volume 15. Oxford: Oxford University Press.

Williamson, L., (1998). Eating disorders and the cultural forces behind the drive for thinness: are African American women really protected? Social Work in Health Care, 28, 61-73.

Wolmarans, P., Langenhoven, M.L., Benade, A.J.S., Swanepoel, A.S.P., Kotze, T.J.v.W., and J.E. Rossouw (1988). Intake of macronutrients and their relationship with total cholesterol and high-density lipoprotein cholesterol. The Coronary Risk Factor Study, 1979. South African Medical Journal, 73, 12-15. 
Table 1: Energy intakes before modification of the MRC South African FFQ.

\begin{tabular}{|l|l|l|l|}
\hline Participant & $\begin{array}{l}\text { Energy } \\
\text { intake } \\
\text { (kcal) }\end{array}$ & \% RDA & BMI \\
\hline Girl & 1681 & 76.4 & 18.90 \\
\hline Girl & 5395 & 245.2 & 23.75 \\
\hline Girl & 4009 & 182.2 & 25.80 \\
\hline Girl & 3309 & 150.4 & 22.04 \\
\hline Mean & 3599 & 163.6 & 22.62 \\
\hline Boy & 6152 & 205.1 & 24.89 \\
\hline Boy & 6590 & 219.7 & 22.90 \\
\hline Boy & 4691 & 156.4 & 21.91 \\
\hline Boy & 6480 & 216.0 & 18.28 \\
\hline Mean & 5978 & 199.3 & 22.00 \\
\hline
\end{tabular}

RDA-Recommended dietary allowance: boys $=3000 \mathrm{kcal}$ and girls $=2200 \mathrm{kcal}$ (Food and Nutrition Board, 1989).

BMI- body mass index $=\left(\right.$ weight $(\mathrm{kg}) /$ height $(\mathrm{m})^{2}$. 
Fig 1: MRC procedure for the Food Frequency Questionnaire.

\section{Interviewer instructions}

Step 1: Start the interview by saying "I want you to think back over the past...... month/s about the foods and drinks you ate/drank. Then I want you to try and remember how much you usually have of each item."

Step 2: Give the participant the Food Flash Cards with the following instruction: "Please look through these photographs and make two piles. One pile is for items, which you never ate/drank in the past month. The other is for those items that you did eat/drink in the past month". Put away the pile of cards that were not eaten or drunk.

Step 3: Now ask the participant to do the following. "Once again make 2 piles of cards. The one pile should include items, which you eat/ drink nearly everyday. The second pile should include those items that are eaten/drunk less frequently, i.e. once a fortnight or once a month."

Steps 4 and 5 are completed together, for each food item, before moving on to the next item:

Step 4: Now proceed through each item of the frequently eaten pile with the participant. Ask about how often the item is usually eaten per day/week. This amount should be entered in the appropriate column in the FFQ. For example, if white bread is usually eaten once a day, every day fill in a ' 1 ' in column $E$ (eaten daily). Items every week (but not every day) should be filled in column $\mathbf{F}$ according to the number of days per week eaten. Less frequently (once a fortnight/once a month) foods should be entered in column G. Do this until all the cards are accounted for.

Step 5: The next step is to determine the portion size of each item. This is done per item as you work through the commonly eaten foods step above. This must be done for each item directly after the frequency of intake was determined (Step 4). The FPM and any other available aids must be used to determine the portion size. Please note that each item has a number that corresponds to the number and colour of the photos in the manual. Identify the appropriate code from the FPM and enter it in column C on the FFQ.

(Steyn, N.P. and M. Senekal (2005). in A guide for the use of the dietary assessment and education kit (DAEK). 
Table 2: Energy intakes after modification of the South African MRC FFQ.

\begin{tabular}{|l|l|l|}
\hline & Girls & Boys \\
\hline Sample size (n) & 42 & 33 \\
\hline Mean age (SD) & $15.3(0.04)$ & $15.3(0.05)$ \\
\hline Mean BMI (SD) & $21.26(3.18)$ & $19.83(2.70)$ \\
\hline BMI range & $16.37-29.31$ & $16.33-28.69$ \\
\hline Mean energy intake (kcal) (SD) & $2677(1006)$ & $2937(1061)$ \\
\hline Median energy intake (kcal) & 2631 & 2645 \\
\hline Mean \% RDA (SD) & $121.0(45.4)$ & $97.9(35.4)$ \\
\hline 95\% Cl \% RDA & $106.8-135.1$ & $85.4-110.4$ \\
\hline
\end{tabular}

BMI: body mass index; SD: standard deviation; RDA: recommended dietary allowance;

Cl: confidence interval 
Table 3: Energy intakes in South African adolescents from this study and other recent studies

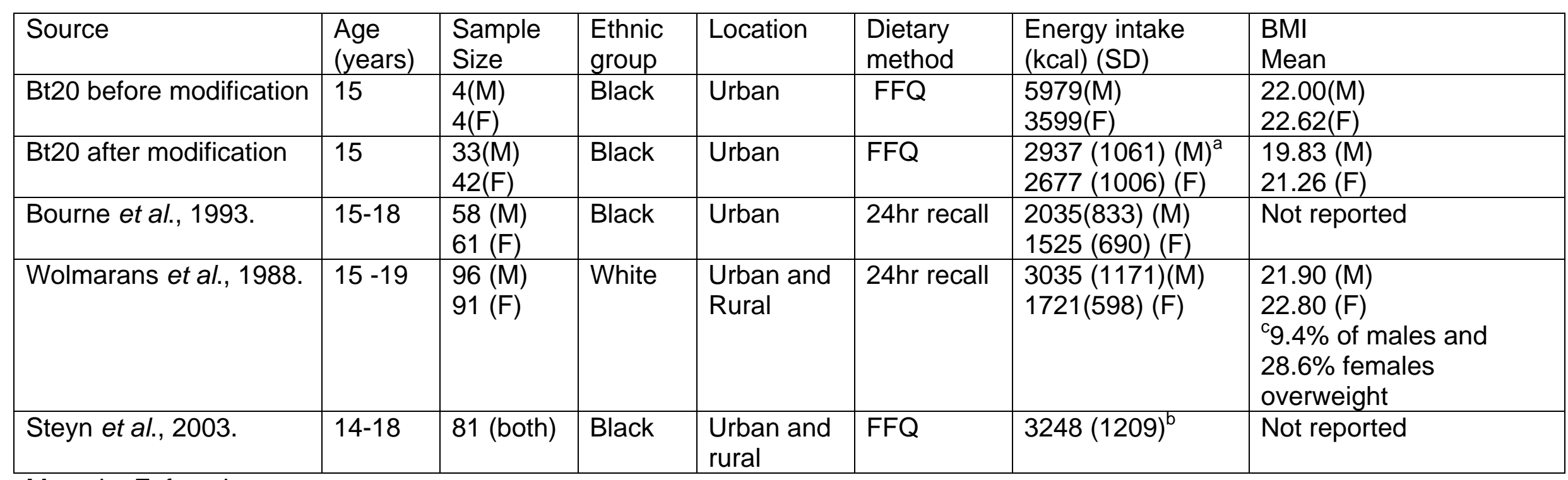

M: male; F: female.

${ }^{a}$ Mean energy intakes fell below the RDA for both males and females.

${ }^{b}$ No breakdown by sex. Data from the THUSA (Transition and Health during Urbanisation of South Africans) study. Original paper (Maclntyre et al., 2002) reports data for all adults up to $>65$ years.

${ }^{\mathrm{C}} \mathrm{BMI}>=25$ in males and $>=24$ in females used to define overweight. 
